\title{
A chemical ionization mass spectrometer for continuous underway shipboard analysis of dimethylsulfide in near-surface seawater
}

\author{
E. S. Saltzman ${ }^{1}$, W. J. De Bruyn ${ }^{2}$, M. J. Lawler ${ }^{1}$, C. A. Marandino ${ }^{1,}$, and C. A. McCormick ${ }^{1}$ \\ ${ }^{1}$ University of California, Irvine, Irvine, California, USA \\ ${ }^{2}$ Chapman University, Orange, California, USA \\ *now at: Leibniz Institut für Meereswissenschaften (IFM-GEOMAR), Kiel, Germany
}

Received: 11 June 2009 - Published in Ocean Sci. Discuss.: 16 July 2009

Revised: 16 October 2009 - Accepted: 19 October 2009 - Published: 6 November 2009

\begin{abstract}
A compact, low-cost atmospheric pressure, chemical ionization mass spectrometer ("mini-CIMS") has been developed for continuous underway shipboard measurements of dimethylsulfide (DMS) in seawater. The instrument was used to analyze DMS in air equilibrated with flowing seawater across a porous Teflon membrane equilibrator. The equilibrated gas stream was diluted with air containing an isotopically-labeled internal standard. DMS is ionized at atmospheric pressure via proton transfer from water vapor, then declustered, mass filtered via quadrupole mass spectrometry, and detected with an electron multiplier. The instrument described here is based on a low-cost residual gas analyzer (Stanford Research Systems), which has been modified for use as a chemical ionization mass spectrometer. The mini-CIMS has a gas phase detection limit of 220 ppt DMS for a 1 min averaging time, which is roughly equivalent to a seawater DMS concentration of $0.1 \mathrm{nM}$ DMS at $20^{\circ} \mathrm{C}$. The mini-CIMS has the sensitivity, selectivity, and time response required for underway measurements of surface ocean DMS over the full range of oceanographic conditions. The simple, robust design and relatively low cost of the instrument are intended to facilitate use in process studies and surveys, with potential for long-term deployment on research vessels, ships of opportunity, and large buoys.
\end{abstract}

\section{Introduction}

Dimethylsulfide (DMS) has an important role in the Earth's climate system as the principle precursor of non-seasalt sulfate aerosol over the oceans. An understanding of the oceanic distribution and emissions of DMS is needed in order to assess the magnitude and direction of future changes in DMS

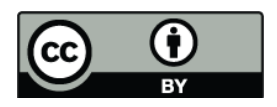

Correspondence to: E. S. Saltzman (eric.saltzman@uci.edu) emissions and the possible climate feedbacks involved. The existing database of surface ocean DMS measurements consists of many thousands of discrete measurements (Kettle et al., 1999). This database has been used as a basis for developing and validating empirical algorithms and biogeochemical models of DMS cycling (Simo et al., 2002). Although the database represents considerable scientific effort by many investigators, it remains extremely limited in terms of both spatial and temporal coverage. A higher resolution global climatology of surface ocean DMS is needed to progress towards a process-level understanding of the biogeochemistry of DMS cycling (Nemcek et al., 2008) and to predict possible future changes in DMS levels.

The existing seawater DMS data are comprised largely of purge and trap measurements of samples collected via Niskin bottles or shipboard pumping systems. Most of these samples were analyzed by gas chromatography with flame photometric or chemiluminescence detection (Andreae and Barnard, 1983; Bates et al., 1987; Turner and Liss, 1985; Dacey et al., 1998). Purge and trap methods typically have a sub-nM detection limits, and an analysis period of several minutes. Park and Lee (2008) coupled a commercial membrane equilibrator to an automated GC/flame photometric detection system for underway analysis of DMS in discrete seawater samples obtained from a shipboard pumping system. Tortell (2005a, b) developed a membrane-inlet mass spectrometer for continuous, underway DMS analysis using a triple quadrupole mass spectrometer. That instrument has a detection limit of $1 \mathrm{nM}$ and a measurement period of $20 \mathrm{~s}$.

In this paper we discuss the use of atmospheric pressure chemical ionization mass spectrometry (APCI-MS) as a detection method for underway seawater DMS measurements. APCI-MS analysis of atmospheric DMS was first done using a tandem mass spectrometer with benzene as the reagent ion (Kelly and Kenny, 1991; Spicer et al., 1996). Bandy et al. (2002) measured atmospheric DMS with APCI using a single quadrupole mass spectrometer, using proton transfer

Published by Copernicus Publications on behalf of the European Geosciences Union. 
from ionized water and water clusters in a heated air stream. In this form, the APCI-MS technique has been used on numerous ground based, airborne, and shipboard campaigns. Marandino et al. (2007, 2008, 2009) made underway surface seawater DMS measurements using a research-grade APCI-MS in conjunction with a continuous flow membrane equilibrator. This paper discusses the design and performance of a much smaller, lower-cost automated APCI-MS instrument specifically designed for measurements of surface ocean DMS from a seawater equilibrator. The design goals for this instrument (hereafter referred to as the "miniCIMS"), were to achieve a detection limit of $0.1 \mathrm{nM}$ DMS in a relatively compact, low cost package with no moving parts and the potential for unattended operation. Although a membrane equilibrator was used in the testing of this instrument, this study did not critically evaluate the performance of the equilibrator.

\section{Principles of operation}

\subsection{DMS detection by APCI-MS}

In this study, the atmospheric pressure chemical ionization of DMS was carried out by passing air over a ${ }^{63} \mathrm{Ni}$ foil, resulting in the formation of protonated water ions and ion clusters, $\left(\mathrm{H}_{2} \mathrm{O}\right)_{n} \mathrm{H}^{+}$. The lower order clusters, i.e. $n=0$, 1 , and 2 , can act as reagent ions, ionizing DMS in the air stream via proton transfer, as follows:

$$
\begin{aligned}
& \mathrm{H}^{+}\left(\mathrm{H}_{2} \mathrm{O}\right)_{\mathrm{n}-1}+\mathrm{H}_{2} \mathrm{O}+\mathrm{N}_{2} \leftrightarrow \mathrm{H}^{+}\left(\mathrm{H}_{2} \mathrm{O}\right)_{\mathrm{n}}+\mathrm{N}_{2} \\
& \mathrm{H}^{+}\left(\mathrm{H}_{2} \mathrm{O}\right)_{\mathrm{n}}+\mathrm{DMS} \leftrightarrow \mathrm{DMSH}^{+}\left(\mathrm{H}_{2} \mathrm{O}\right)_{\mathrm{m}}+(\mathrm{n}-\mathrm{m}) \mathrm{H}_{2} \mathrm{O}
\end{aligned}
$$

Heating the ionization region shifts the equilibrium charge distribution of water ions to favor lower order water vapor clusters, which have lower proton affinities and more readily transfer $\mathrm{H}^{+}$to DMS (Sunner et al. 1988a, b). After the source region, some of the ionized gas stream is drawn into a 1 Torr region in which ions are declustered via collision with air molecules. Finally, the ions are drawn and electrostatically steered into a low pressure region where they are mass filtered using a quadrupole mass spectrometer and detected using an electron multiplier. In this study, DMS was detected as the $\mathrm{CH}_{3} \mathrm{SCH}_{3} \mathrm{H}^{+}$ion at $\mathrm{m} / \mathrm{z} 63 . \mathrm{CH}_{3} \mathrm{SCD}_{3}$ was used as an internal standard, and was detected as $\mathrm{CH}_{3} \mathrm{SCD}_{3} \mathrm{H}^{+}$at $\mathrm{m} / \mathrm{z} 66$.

\subsection{Equilibration of seawater DMS with air}

A gas/liquid equilibrator is used to obtain a stream of air with a DMS partial pressure equal to that in the ships scientific seawater supply. Many different type of equilibrators have been used to measure gases in seawater, including bubblers, shower-head type, and membrane equilibrators. In principle, the APCI-MS instrument can be used with any type of gas/liquid equilibrator capable of delivering a sufficient stream of equilibrated air. Because DMS is moderately soluble in seawater, equilibrium is achieved rapidly in most equilibrators. In this study, a flow-through, single tube membrane equilibrator was used. The membrane was a hydrophobic, porous polymer tube with seawater flowing around it, and air counter-flowing through it. Dissolved gases diffuse across the pores in the tube wall into the air stream, and the exiting air stream is equilibrated with the DMS in the seawater. At the gas and liquid flow rates used in this study, depletion of the DMS in the seawater flow is negligible. In this study, the geometry of the equilibrator permitted an air flow rate of only $60 \mathrm{ml} \mathrm{min}^{-1}$ (see Sect. 3.2) well below the optimal flow rate required by the mass spectrometer source. To make up the difference, an additional flow of clean, dry air was added to the equilibrated air stream as a dilution gas.

\subsection{Calculation of seawater DMS levels}

The mass spectrometer signals provide a measure of the mixing ratio in the diluted equilibrated air stream. The DMS concentration in the seawater in the equilibrator is calculated from this mixing ratio, equilibrator temperature, and salinity. We used the expression for DMS solubility determined by Dacey et al. (1984). Depending on conditions, the temperature of the equilibrator in a shipboard flow-through system can vary from ambient sea surface temperature by $1^{\circ} \mathrm{C}$ or more. The ambient DMS mixing ratio in the analyzed gas stream $\left(X_{\mathrm{DMS}}\right)$ is determined as follows:

$X_{\mathrm{DMS}}=\frac{S_{63}}{S_{66}} \frac{F_{\text {total }}}{F_{\mathrm{EQ}}} X_{\text {iso }} \frac{F_{\text {iso }}}{F_{\text {total }}}$

where $S_{63}$ and $S_{66}$ represent the blank-corrected mass spectrometer signals from ambient and isotope- labeled DMS, $F_{\mathrm{EQ}}$ is the mass flow rate through the equilibrator, $F_{\text {total }}$ is the total mass flow rate (equilibrator+dilution gas+isotopically labeled DMS), $F_{\text {iso }}$ is the mass flow rate of the isotopelabeled DMS, and $X_{\text {iso }}$ is the mixing ratio of isotopicallylabeled DMS in the standard cylinder, The gas phase DMS mixing ratio is converted to seawater concentration via:

$[\mathrm{DMS}]=X_{\mathrm{DMS}} P_{\mathrm{atm}} H_{\mathrm{DMS}}$

where $P_{\text {atm }}$ represents the ambient atmospheric pressure in atmospheres, and $H$ is the temperature and salinitydependent Henry's law constant for DMS $\left(\mathrm{M} \mathrm{atm}^{-1}\right)$. In this calculation, $H$ is computed using the temperature of seawater measured in the equilibrator, and salinity from the ship's underway flow-through system.

The partial pressure of DMS at the sea surface can be calculated from the DMS concentration using the Henry's law constant computed for the ambient sea surface temperature, as follows.

$P_{\text {DMS-seasurface }}=\frac{[\mathrm{DMS}]}{H_{\mathrm{DMS}}}$ 


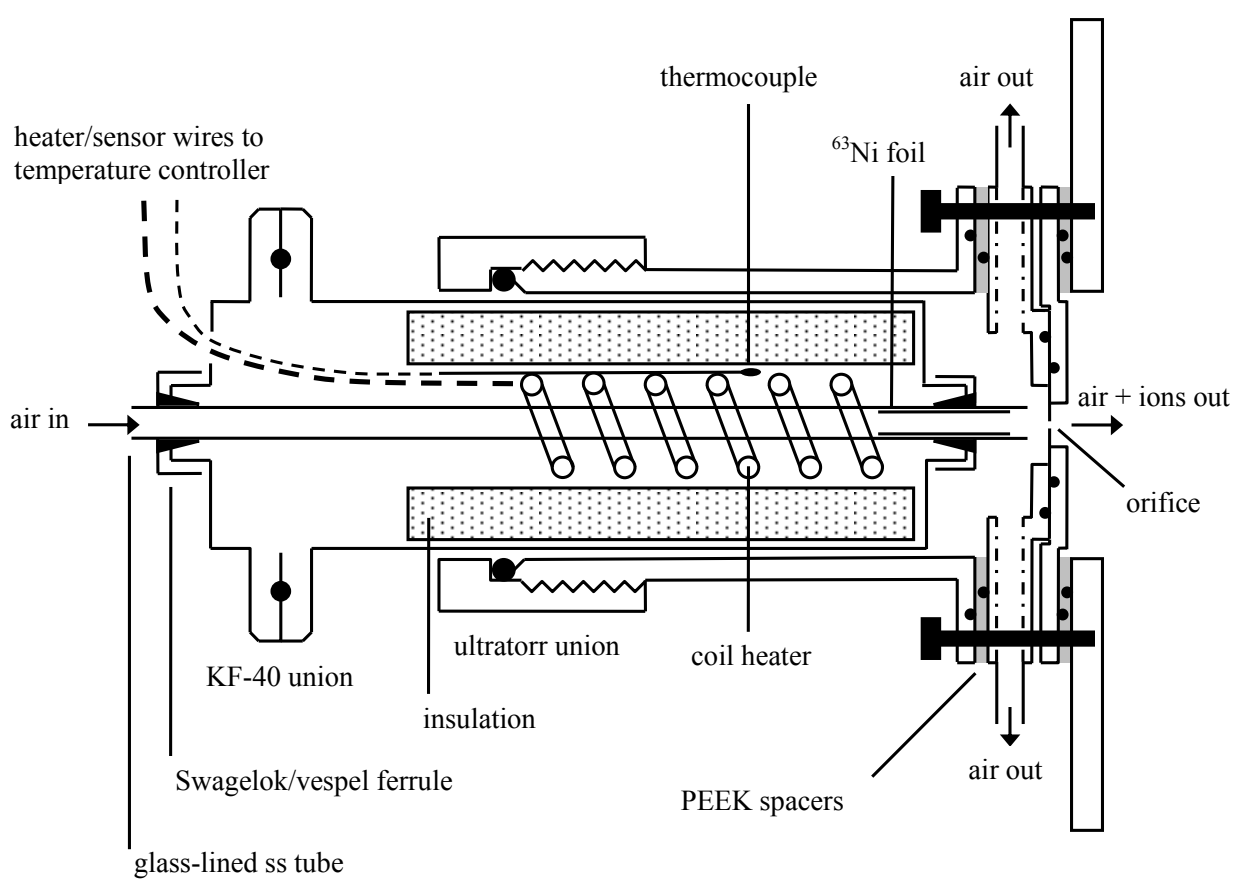

Fig. 1. Schematic of the ion source of the mini-CIMS instrument.

\section{Instrument design}

\subsection{Mini-CIMS mass spectrometer}

The instrument consists of three stages: a source region (101.3 kPa; 760 Torr), a collision region $(1.33 \mathrm{hPa} ; 1$ Torr), and an analyzer region $\left(1.33 \mathrm{mPa} ; 10^{-5}\right.$ Torr $)$. The instrument is housed in a custom $20.3 \mathrm{~cm}\left(8^{\prime \prime}\right)$ diameter stainless steel vacuum chamber. The chamber and most of the components described below were fabricated in house. The source region consists of a glass-lined stainless steel $6.35 \mathrm{~mm}\left(1 / 4^{\prime \prime}\right)$ OD tube surrounded by a coil heater, thermocouple, and molded high temperature insulation (Fig. 1). This heated inlet tube is packaged in a $3.2 \mathrm{~cm}\left(1 / 4^{\prime \prime}\right)$ OD stainless steel tube and mounted on the instrument via an ultra-Torr fitting, electrically isolated from the instrument by a PEEK ring. The sampled air exits the source via two $6.35 \mathrm{~mm}\left(1 / 4^{\prime \prime}\right)$ OD tubes, at right angles to the inlet tube. Air can either be drawn through the source using a diaphragm pump or forced through the source under pressure. The source was operated at a temperature of $673 \pm 1 \mathrm{~K}\left(400 \pm 1^{\circ} \mathrm{C}\right)$ using a proportional temperature controller in pulse mode, with a solid state relay (model CN8201, Omega Engineering, Stamford, CT). The general design of this source is similar to that used by Marandino et al. (2007).

Ions enter the mass spectrometer via a $255 \mu \mathrm{m}$ orifice in a stainless steel disc $(0.1 \mathrm{~mm}$ thickness, grade 316$)$, electrically isolated from the source inlet and mass spectrometer by PEEK rings. The orifice allows an air flow of approximately $8.33 \mathrm{~cm}^{3} \mathrm{~s}^{-1}\left(500 \mathrm{~cm}^{3} \mathrm{~min}^{-1}\right)$ into the collision re- gion (Fig. 2). All gas flow rates are expressed as volume flow at standard temperature and pressure. The collision region consists of two stainless steel conical lenses, approximately $6 \mathrm{~mm}$ apart, with apertures of $1 \mathrm{~mm}$ and $100 \mu \mathrm{m}$. The distance between the orifice and first conical lens is determined by the thickness of the PEEK spacer between the orifice and collision region. To optimize ion transmission, the aperture of the first conical lens is placed inside the zone of silence of the expanding jet of gas exiting the orifice into the 1 Torr region (Campargue, 1984). The collision region is pumped by a rotary vane pump through two $2.54 \mathrm{~cm} \mathrm{(1")}$ ports (E2M28, Edwards, West Sussex, UK). The potential difference between the conical lenses controls the collision energy, and the second conical lens serves as the restricting orifice for the passage of gas (neutrals and ions) into the analyzer region. The flow rate into the analyzer region is approximately $0.006 \mathrm{~cm}^{3} \mathrm{~s}^{-1}\left(0.36 \mathrm{~cm}^{3} \mathrm{~min}^{-1}\right)$. The cone lens voltages are supplied through a high vacuum, 10-conductor electrical feedthrough mounted on a $2.54 \mathrm{~cm}\left(1^{\prime \prime}\right)$ conflat flange on the front face of the collision chamber.

In the analyzer chamber, ions are electrostatically steered towards the quadrupole using four lenses. The first is a tube lens made of stainless steel mesh $(1 \mathrm{~mm}$ mesh, $2 \mathrm{~cm}$ long, $1 \mathrm{~cm} \mathrm{ID).} \mathrm{Next} \mathrm{are} \mathrm{three} \mathrm{flat} \mathrm{aperture} \mathrm{lenses} 1 \mathrm{~mm}$ thick, with a central orifice of $1 \mathrm{~cm}$. These lenses are spaced approximately $6 \mathrm{~mm}$ apart. They are mounted on four \#8 stainless steel threaded rods, and electrically isolated with PEEK spacers. The lens assembly is clamped to the outside of a $15 \mathrm{~cm}$ long, $3.81 \mathrm{~cm}$ OD $\left(1.5^{\prime \prime}\right), 3.48$ ID stainless steel tube welded onto the back flange of the analyzer chamber. This mounting 


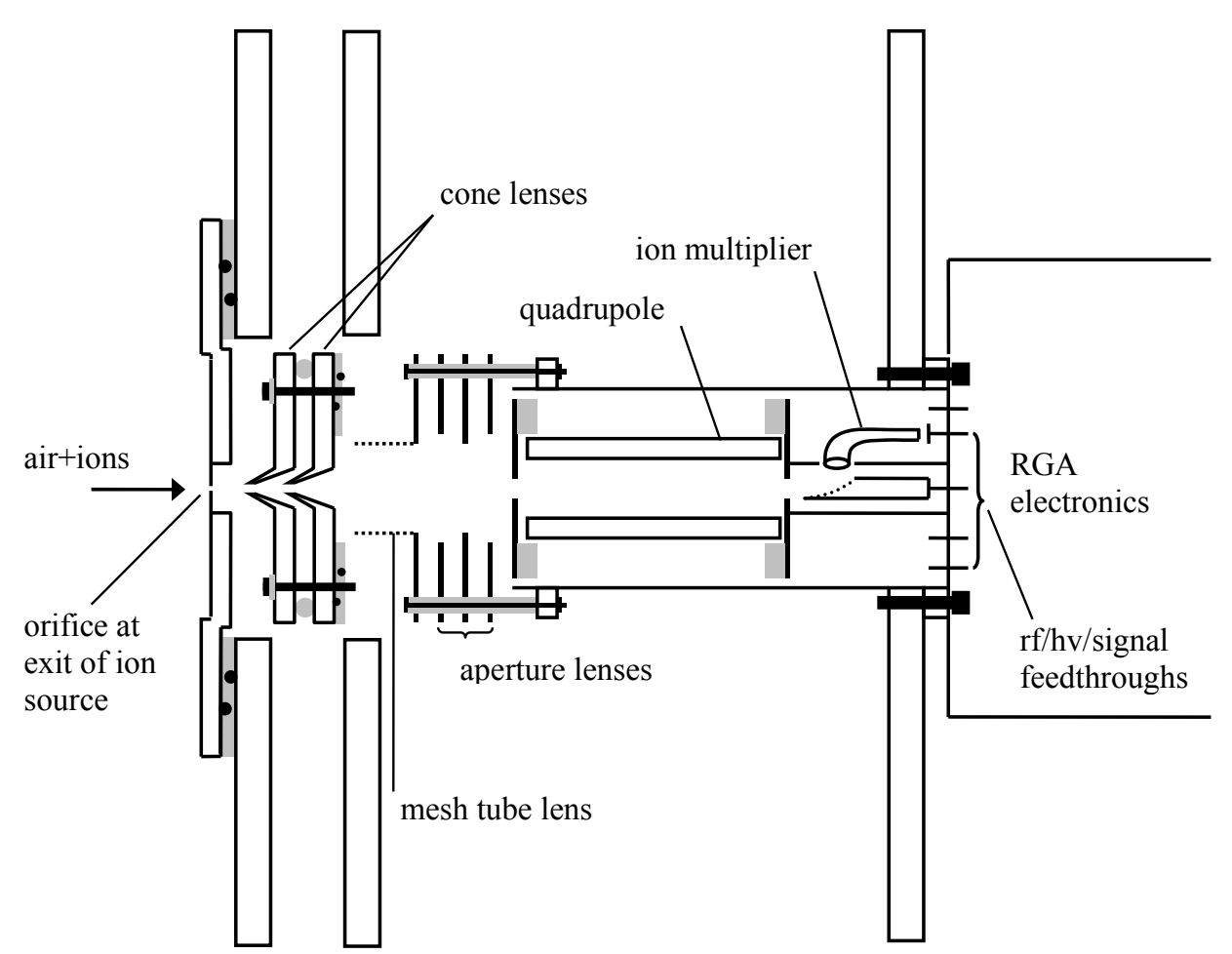

Fig. 2. Schematic diagram of the collision chamber and high vacuum region containing the quadrupole mass spectrometer and ion multiplier. The direction of travel of ions is left to right, and the leftmost orifice here is the same as the rightmost orifice in Fig. 1.

tube also serves as the housing for the quadrupole mass spectrometer. The lens voltages are provided via a second high vacuum, 10-conductor electrical feedthrough mounted on the rear flange of the instrument. The lens potentials used to obtain optimal sensitivity for DMS are shown in Table 1.

The quadrupole mass filter, detector, and detector electronics were provided by a residual gas analyzer (RGA200, Stanford Research Systems, Sunnyvale, CA). To our knowledge, this instrument has not previously been used for analytical APCI-MS applications of this type. The commercially available SRS RGA is supplied with an electron impact source. The instrument was modified in our laboratory by removing all structural components of its electron impact source, consisting of the filament, repeller, and supporting rods. The remaining instrument consists of an entrance lens, quadrupoles $(6.35 \mathrm{~mm}$ diameter, $15.24 \mathrm{~cm}$ long), exit lens, Faraday cup and ion multiplier. The RGA is inserted into the instrument through the back flange into the $3.81 \mathrm{~cm}$ OD tube mentioned earlier. The dimensions of this tube match those of a standard conflat nipple in which the RGA is normally housed, and for which the RGA radio frequency electronics are factory tuned. The analyzer chamber is pumped by a $550 \mathrm{~L} \mathrm{~s}^{-1}$ turbomolecular pump (Turbo-V 551 Navigator, Varian Inc., Palo Alto, CA, USA), backed by the same rough pump used to pump the collision chamber.
Table 1. Typical lens potentials used on the mini-CIMS.

\begin{tabular}{|c|c|c|}
\hline Location (pressure) & Lens & Potential (V DC) \\
\hline Ion source ( 760 Torr) & pinhole & 45.0 \\
\hline \multirow[t]{2}{*}{ Collision region (1 Torr) } & cone 1 & 40.0 \\
\hline & cone 2 & 25.0 \\
\hline \multirow[t]{5}{*}{ Analyzer region $\left(10^{-5}\right.$ Torr $)$} & mesh 1 & -13.5 \\
\hline & aperture 2 & -36.0 \\
\hline & aperture 3 & -160.0 \\
\hline & aperture 4 & 15.0 \\
\hline & focus plate & -10.0 \\
\hline
\end{tabular}

The SRS RGA has an integrated electronics package $(10 \times 15.2 \times 23 \mathrm{~cm})$ that mounts directly to the mass spectrometer flange outside the vacuum system. The components needed for this instrument are: a RF/DC circuit to drive the quadrupole mass filter, a DC lens supply voltage for the entrance lens, and an electrometer for amplifying the electron multiplier current. The instrument was operated with an ion multiplier voltage of $1800 \mathrm{~V}$, resulting in a gain of approximately $10^{6}$. The embedded firmware of the SRS RGA tests for filament emission current during startup, as a protection 
against overpressure and filament burnout. Removal of the electron impact source results in failure of this test. To overcome this protection, we supplied an appropriate voltage to to the RGA circuitry to simulate the presence of a working filament, as described in the supplementary material http://www. ocean-sci.net/5/537/2009/os-5-537-2009-supplement.pdf.

\subsection{Membrane equilibrator}

The membrane equilibrator used in this study was a homemade device consisting of a porous Teflon tube mounted inside of a coiled, $1 \mathrm{~m}$ long, $12.7 \mathrm{~mm}\left(1 / 2^{\prime \prime}\right)$ OD PFA Teflon tube. The porous tube was $3.175\left(1 / 8^{\prime \prime}\right) \mathrm{ID} \times 1 \mathrm{~m}$ long, with $40-80 \mu \mathrm{m}$ optical internodal distance, and density of $<0.35 \mathrm{~g} \mathrm{~cm}^{-3}$ (International Polymer Engineering, Tempe, Arizona). The equilibrator was connected to air and seawater flows using "T"-fittings at each end. This allowed seawater to flow around the membrane tube in counterflow to the air flowing inside the membrane tube. This device achieves full equilibration for DMS at gas flow rates of up to $60 \mathrm{~cm}^{3} \mathrm{~min}^{-1}$. This is demonstrated empirically by varying the flow rate and observing the resulting signal. An equilibrator of this general type (although not the specific dimensions) has been used in several field projects with no evidence of biofouling, even in bloom conditions (Marandino et al., 2007, 2008). The principle disadvantages of this type of membrane equilibrator are the limited flow rates and low bubble breakthrough pressure. It is critical to maintain strong seawater flow through the equilibrator tube to maintain sufficient back pressure to inhibit bubble breakthrough. Seawater flow rates of 2 or more $\mathrm{L} \mathrm{min}^{-1}$ were sufficient for this purpose.

\subsection{System layout}

A schematic of the layout of the system is shown in Fig. 3. DMS-free air was supplied to the equilibrator from a clean air generator with a heated catalyst for hydrocarbon removal (Aadco Instruments, Cleves, $\mathrm{OH}$ ). A second stream of clean air, at approximately $28.3 \mathrm{~cm}^{3} \mathrm{~min}^{-1}\left(1700 \mathrm{~cm}^{3} \mathrm{~min}\right)$, was used as a make-up gas to dilute the output of the equilibrator. A small flow of $0.033 \mathrm{~cm}^{3} \mathrm{~s}^{-1}\left(2 \mathrm{~cm}^{3} \mathrm{~min}^{-1}\right)$ of $2 \mathrm{ppm}$ $\mathrm{CD}_{3} \mathrm{SCH}_{3}$ in $\mathrm{N}_{2}$ was added to the gas stream just after the equilibrator to serve as an internal standard. The flow rate of the internal standard was adjusted to yield a signal similar to that of ambient DMS. All gas flows were mass flow controlled. Seawater was supplied from the scientific seawater system of the research vessel.

The gas flows to and from the equilibrator were supplied via 3-way PFA electrically-actuated diaphragm valves. These valves were switched together to bypass the equilibrator, providing a system blank which includes the tubing leading to the APCI-MS and any impurities in the Aadco air stream. A third 3-way valve was used to vent the isotopically-labeled gas standard to waste, so the standard

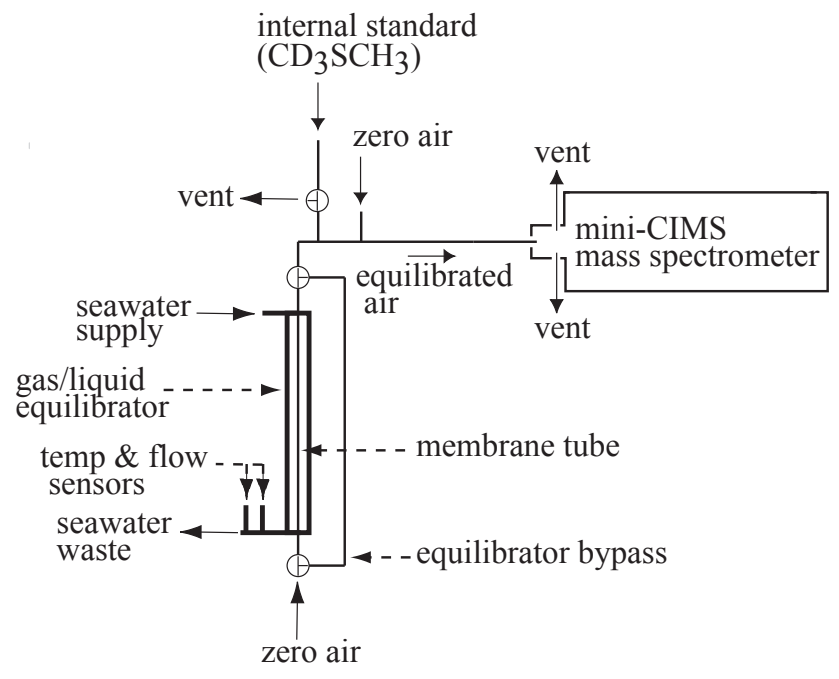

Fig. 3. Plumbing schematic for the mini-CIMS and membrane equilibrator as deployed on the Knorr 2007 cruise.

blank could be measured. In routine operation, these blanks were monitored for approximately 30 minutes every $12 \mathrm{~h}$.

Impermeable (copper) tubing is used to deliver Aadco air to the equilibrator to avoid contamination from air in the vessel. The equilibrated air is delivered to the APCI-MS via either Teflon (PFA) or Dekabon tubing, depending on the length. The equilibrator and APCI-MS units need not be co-located. On the R/V Knorr 2007 deployment, the units were separated by approximately $30 \mathrm{~m}$, with the equilibrator located on the main deck and the ACPI-MS located in a van on the upper deck.

\subsection{Data acquisition and control}

The instrument user interface is a custom Labview program (National Instruments, Austin, TX) running under Windows on a laptop PC. This program communicates with the Stanford Research Systems RGA via RS232 serial communication. The software allows setup of quadrupole entrance lens, ion multiplier voltages, and configuration of run parameters for data acquisition in scanning and selected ion monitoring modes. The program also provides control of external devices and data logging via a USB multifunction IO module (UE9, Labjack Corp. Lakewood, CO) and custom interface electronics. These functions include: control/logging of up to 8 analog mass flow controllers, control of ion lens DC voltages, solenoid valve switching, and data logging of the APCI ion source temperature, and 1 Torr region pressure. The equilibrator seawater flow rate is also logged using a paddlewheel flow meter (Gems Sensors and Controls, Plainville, CT) by pulse counting via the Labjack UE9. Equilibrator temperature is logged via RS232 serial communication from a digital thermometer. The custom electronics used to control lens voltages and mass flow controllers was designed by the 


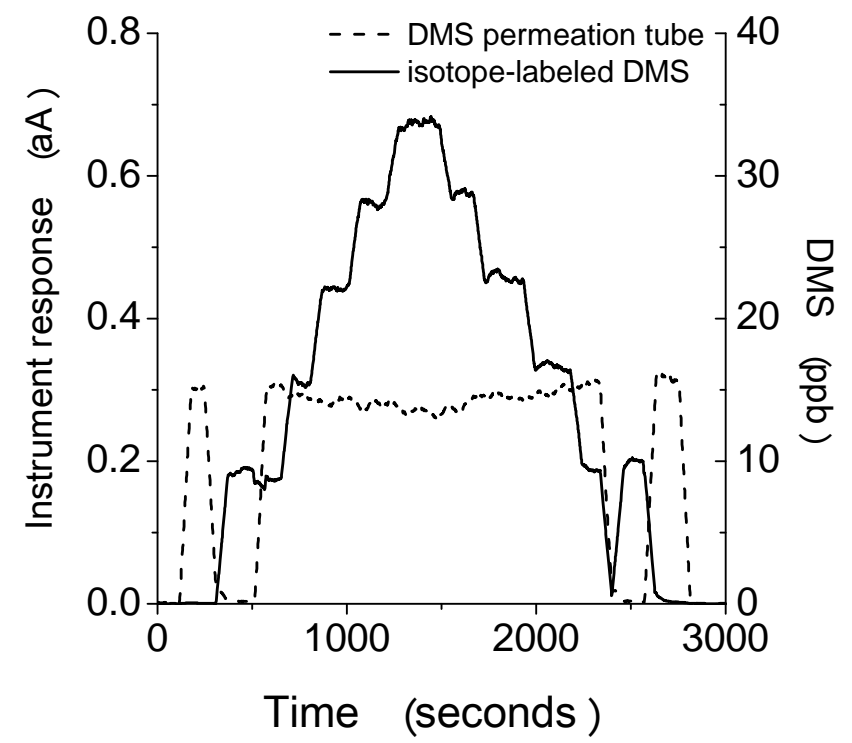

Fig. 4. Instrument response during calibration of the isotopelabeled $\mathrm{CH}_{3} \mathrm{SCD}_{3}$ standard at various flow rates $(\mathrm{m} / \mathrm{z}=66)$, with a constant flow from the output of a $\mathrm{CH}_{3} \mathrm{SCH}_{3}$ permeation tube $(\mathrm{m} / \mathrm{z}$ $=63$ ). Brief periods of internal standard only and permeation tube only are run before and after the calibration run.

UCI Instrument Development Facility (detailed information available from the author on request).

\subsection{Calibration}

The primary standards for this system are DMS permeation tubes maintained at constant temperature in the laboratory and weighed weekly. The working standards used in the field are 6 and $30 \mathrm{dm}^{3}$ high pressure aluminum cylinders of 15 ppm $\mathrm{CH}_{3} \mathrm{SCD}_{3}$ in $\mathrm{N}_{2}$ prepared in our laboratory and delivered with high purity stainless steel regulators. The working standards are calibrated before and after field deployments. Multiple cylinders can be used in order to assess drift in the field. Mass flow controllers are calibrated in the field using a digital bubble flow meter.

\subsection{Laboratory calibration of working standards and detection limits}

Laboratory calibration of the working $\mathrm{CH}_{3} \mathrm{SCD}_{3}$ gas standard was carried out by comparing it to the output of a gravimetrically-calibrated DMS permeation tube. This was done using the mini-CIMS before and after field deployment. The procedure for calibration involves providing a gas flow of $25 \mathrm{~cm}^{3} \mathrm{~s}^{-1}\left(1500 \mathrm{~cm}^{3} \mathrm{~L} \mathrm{~min}^{-1}\right.$ of Aadco air to the miniCIMS inlet. The output of a DMS permeation tube diluted in $\mathrm{N}_{2}\left(30 \mathrm{ng} \mathrm{min}{ }^{-1}\right.$ DMS in $1.66 \mathrm{~cm}^{3} \mathrm{~s}^{-1}$ or $100 \mathrm{ml} \mathrm{min}^{-1}$ $\mathrm{N}_{2}$ ) was teed into the air stream, giving a final mixing ratio of approximately $12 \mathrm{ppb}$. The $\mathrm{CH}_{3} \mathrm{SCD}_{3}$ internal standard was also added to the air stream, at gas flow rates varying

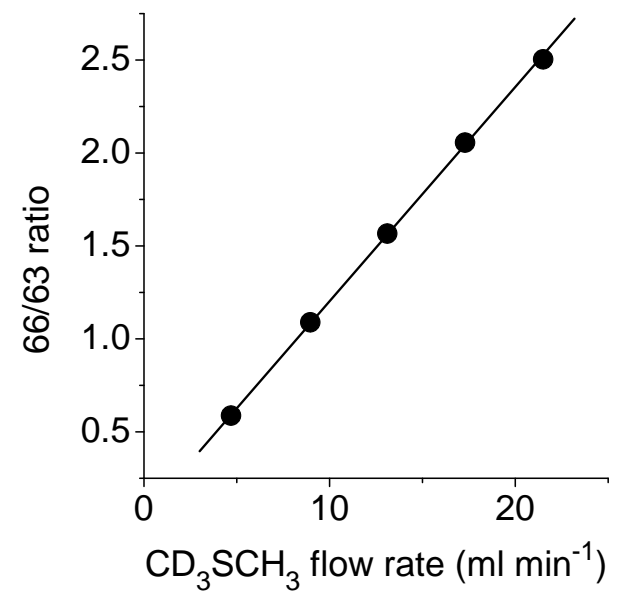

Fig. 5. Calibration of the isotope-labeled DMS $\left(\mathrm{CD}_{3} \mathrm{SCH}_{3}\right)$ gas standard against a DMS $\left(\mathrm{CH}_{3} \mathrm{SCH}_{3}\right)$ permeation tube. These data were obtained by averaging the data shown in Fig. 4 . The $\pm 1 \sigma$ error bars lie within the plotted symbols.

from $0-0.33 \mathrm{~cm}^{3} \mathrm{~s}^{-1}\left(0-20 \mathrm{~cm}^{3} \mathrm{~min}^{-1}\right)$. The resulting mass spectrometers signals at $\mathrm{m} / \mathrm{z} 63$ and 66 were recorded in selected ion monitoring mode (Fig. 4). A minor correction is made to the raw data, to account for the contribution to mass 63 from unlabeled DMS impurity in the isotope-labeled standard (about $2 \%$ of the signal at mass 66 ). The magnitudes of these corrections are determined empirically by analyzing the permeation tube and gas cylinder separately. A calibration curve is obtained from a linear regression of the corrected 63/66 ratio against the flow rate of the $\mathrm{CH}_{3} \mathrm{SCD}_{3}$ working gas standard (Fig. 5). The slope of this line represents the response of the isotope labeled standard relative to the permeation tube, as follows:

$m=\frac{\operatorname{amps}_{66}}{\operatorname{amps}_{63}}\left(\frac{\min }{\mathrm{ml}}\right)_{\text {isotope- }- \text { labeled sandard }}$

The mixing ratio of the standard is obtained from the following calculation:

$X_{\text {iso }}=\frac{m \times E_{\text {perm }}}{n}$

in which $X_{\text {iso }}$ is the mixing ratio of $\mathrm{CH}_{3} \mathrm{SCD}_{3}$ in the working standard cylinder, $E_{\text {perm }}$ is the emission rate of the permeation tube (in moles $\mathrm{min}^{-1}$ ), and $n$ is the number of moles of $\mathrm{N}_{2}$ per ml.

The observed signal variability in the laboratory calibration ranges from 37-90 ppt ( $1 \sigma)$ over the range of 10-35 ppb DMS. Signal variance tends to increase with increasing DMS signal (Figs. 4 and 5). The most likely causes are gas flow rate fluctuations in the equilibrator or inlet, gas turbulence affecting ion transmission in the instrument, and mass spectrometer electronic drift. Because field measurements involve the ratio of two measurements (m/z 63 and 66), the 


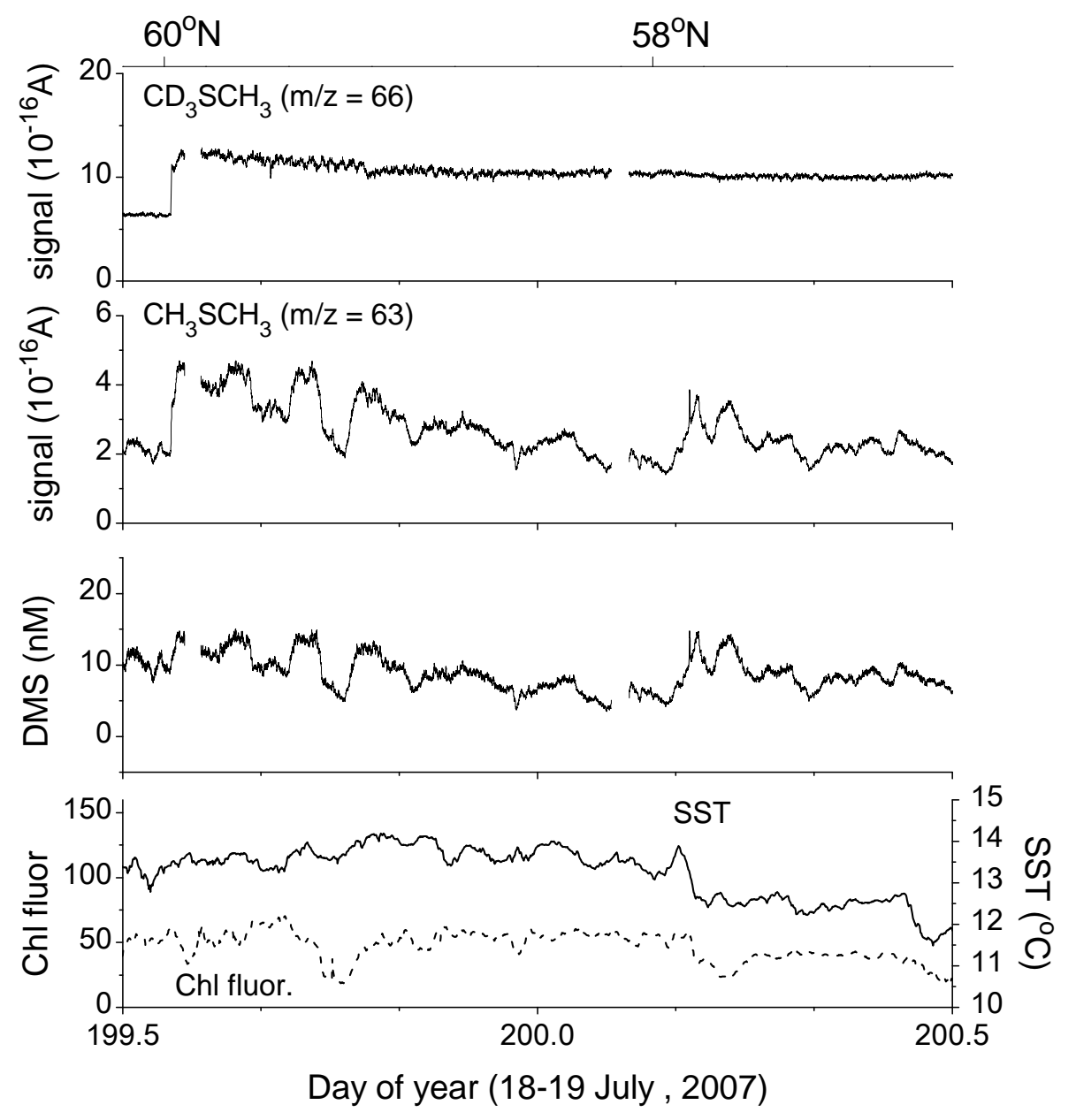

Fig. 6. Underway shipboard measurements from the mini-CIMS instrument heading southeast from Iceland for a $24 \mathrm{~h}$ period on $18-19$ July 2007. From top: 1) raw signal for the stable isotope-labeled DMS internal standard, 2) raw signal from ambient DMS, 3) ambient seawater DMS concentration, 4) sea surface temperature and shipboard flow-through chlorophyll fluorescence.

variance of an ambient DMS measurement is approximately twice that of either ion. Based on the laboratory data, we estimate an upper limit for the detection limit of $148 \mathrm{ppt}$ $(\mathrm{S} / \mathrm{N}=2)$. Under field conditions, the signal variance is slightly larger than in the laboratory. This increased instrument noise is most likely due to motion, thermal effects, or electrical noise (Fig. 6). Using the observed variability in the field data at a DMS level of $10 \mathrm{ppb}$, we estimate a detection limit of 220 ppt. Based on the seawater solubility, this would be equivalent to aqueous concentrations of $0.12,0.10$, and $0.08 \mathrm{nM}$ DMS at temperatures of 15,20 , and $25^{\circ} \mathrm{C}$.

Under field conditions, the instrument response may vary as a function of sea surface temperature, as a result of changes in water vapor level in the analyzed gas stream, which in turn influence the abundance of $\mathrm{H}_{3} \mathrm{O}^{+}$in the ion source. During the field deployment described below, instrument sensitivity increased by about $10 \%$ over a sea surface temperature range from 9 to $15^{\circ} \mathrm{C}$. In principle, it would be possible to eliminate the water vapor dependence and im- prove sensitivity at low sea surface temperature by adding water vapor to the dilution air.

\section{Shipboard performance of the mini-CIMS instru- ment}

\subsection{Operational cycle for field measurements}

For underway field measurements, the instrument is programmed to continuously execute an operational cycle consisting of a long period of equilibrator measurements of ambient DMS, followed by several shorter intervals consisting of several types of system blanks. The blanks are used for corrections in the computation of seawater DMS levels, and the ion scans are used for quality control purposes. The operational cycle used in the field is as follows:

1) seawater equilibrator measurement - equilibrator is inline, internal standard is flowing. Data acquisition $-12 \mathrm{~h}$ in 
single ion monitoring mode, at $\mathrm{m} / \mathrm{z}=63$ and 66 , followed by 5 min of ion scan from 10-100 amu.

2) blank - equilibrator in-line, no internal standard. Data acquisition $-5 \mathrm{~min}$ in single ion monitoring mode $(\mathrm{m} / \mathrm{z}=63$, 66), followed by $5 \mathrm{~min}$ of ion scan (10-100 amu).

3) blank - equilibrator off-line, no internal standard (Aadco clean air only). Data acquisition $-5 \mathrm{~min}$ in single ion monitoring mode $(\mathrm{m} / \mathrm{z}=63,66)$, followed by $5 \mathrm{~min}$ of ion scan (10-100 amu).

4) blank - equilibrator off-line, with internal standard. Data acquisition - $5 \mathrm{~min}$ in single ion monitoring mode $(\mathrm{m} / \mathrm{z}$ $=63,66)$, followed by $5 \mathrm{~min}$ of ion scan $(10-100 \mathrm{amu})$.

Steps 2, 3, and 4 were used to account for the contribution of unlabeled DMS in the internal standard and to detect DMS contamination in the system tubing. These were very small corrections, and minor contributors to the overall uncertainty of the measurements. It is important to note that these blanks do not account for any contamination of the equilibrator itself. Obtaining a true blank on the equilibrator would require the use of DMS-free seawater (or synthetic seawater). In theory, it would be possible to set up such a system, but it was not done in this study.

\subsection{Instrument performance at sea aboard the $\mathrm{R} / \mathrm{V}$ Knorr}

The instrument was field tested for shipboard use on the R/V Knorr during a cruise from Iceland to Woods Hole, Massachussetts (17-24 July 2007). The full data set is discussed by Marandino et al. (2008). Data collected during 18-19 July of the Iceland-Woods Hole cruise are shown here to illustrate the performance of the instrument under field conditions (Fig. 6). The shift in instrument response early in the data set shown (DOY 199.6; at $60^{\circ} \mathrm{N}$ ), was caused by retuning the lens voltages to maximize ion transmission. No further tuning was done to the instrument for the remainder of the cruise. As shown in Fig. 4, the instrument response to DMS is very stable given consistent environmental conditions. As discussed by Marandino et al. (2007), variations in ambient absolute humidity between the tropics and high latitudes can influence APCI-MS response to DMS, by affecting the water vapor content of both the equilibrator outflow and the dilution air from the Aadco clean air generator. The DMS measurement is insensitive to such changes in instrument response because they affect both the ambient DMS and isotopically-labeled internal standard.

The two brief gaps in the data set shown are the periods during which scans and blanks were collected. The ion spectra collected every twelve hours were used for quality control purposes, to assess the cleanliness of the gas stream, and to monitor the resolution and mass calibration of the mass spectrometer (Fig. 7). The ion spectra collected during this cruise were always dominated by the $\left(\mathrm{H}_{2} \mathrm{O}\right)_{2} \mathrm{H}^{+}$(mass 37) peak and a smaller peak from $\left(\mathrm{H}_{2} \mathrm{O}\right)_{3} \mathrm{H}^{+}$(mass 55). The size of the water peaks is a function of the water vapor content of

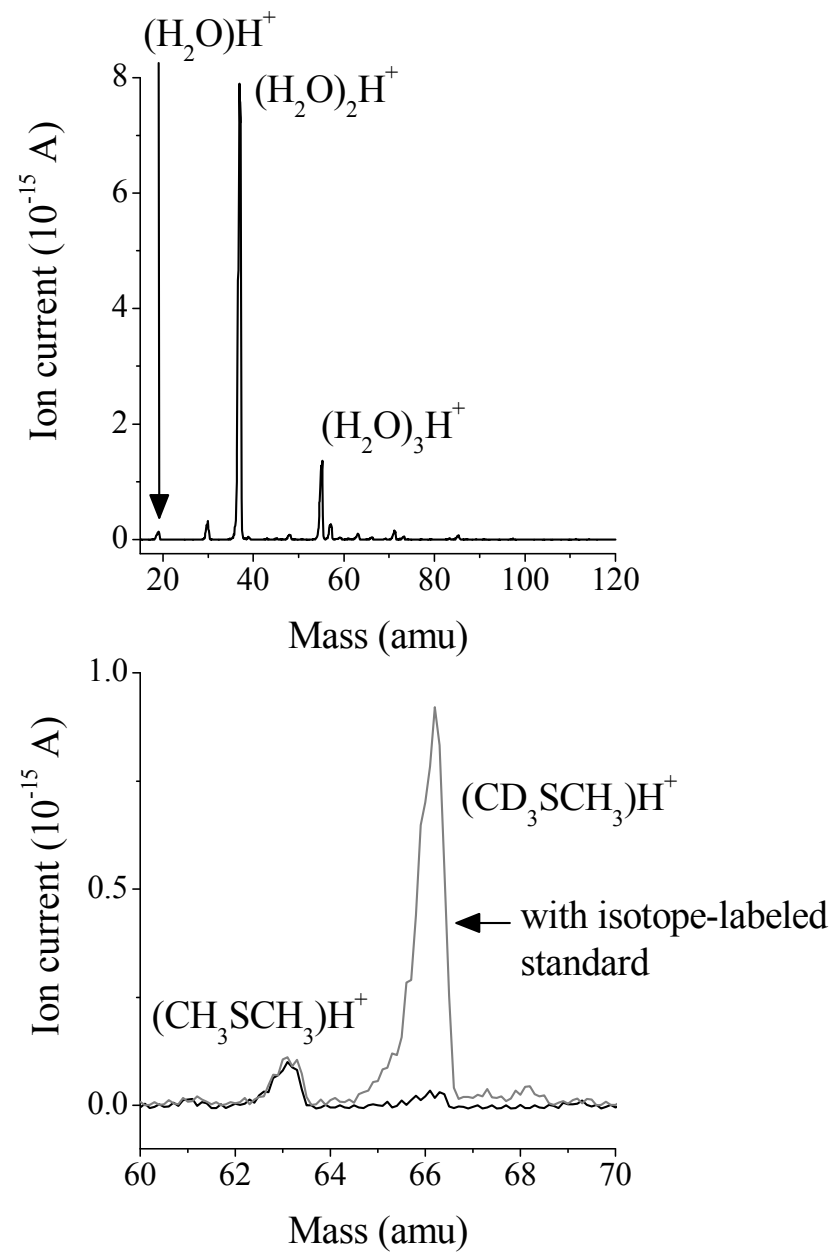

Fig. 7. Ion scans from the mini-CIMS collected during the Iceland-Woods Hole cruise. Top: 15-120 amu scan of seawaterequilibrated air with dilution air, Bottom: 60-70 amu scan of seawater-equilibrated air with dilution air, with and without addition of $\mathrm{CD}_{3} \mathrm{SCH}_{3}$ internal standard.

the air stream, the ion source temperature, and the collision energy in the 1 Torr region.

The ion spectrum is particularly sensitive to the presence of ammonia, which appears as $\mathrm{NH}_{4}^{+}$at mass 18 . Because of its high proton affinity, ammonia efficiently scavenges charge from water cluster ions and suppresses the DMS signal. The effect of ammonia contamination is often observed in the laboratory if the system is opened or if Teflon inlet tubing is used. This effect is not observed if impermeable tubing such as dekabon or copper is used for delivery of zero air to and from the equilibrator. The ammonia naturally present in surface seawater is not sufficiently high to cause this effect. 


\section{Discussion}

This study has demonstrated that the mini-CIMS instrument has the sensitivity, selectivity, and time response required for underway measurements of surface ocean DMS. The robust design and relatively low cost of the instrument make it feasible to consider unattended deployment on research vessels, ships of opportunity, and large buoys. For DMS, this would mean a dramatic increase in data coverage and a data set with which to validate ocean biogeochemical models of increasing complexity. Perhaps more importantly, such a data set could begin the process of taking a "snapshot" of the DMS distribution in the current ocean state, while ocean acidification and global warming are at an early stage.

Further optimization of the instrument could be carried out to improve sensitivity and further downsize the instrument. Areas of potential improvement include more efficient ion source design and improved ion optics for better ion throughput. A simple method of increasing sensitivity of the instrument in its current state would be the construction of a gas/liquid equilibrator that provide higher gas flow rates, reducing the need for dilution of the equilibrated air.

This study focused primarily on the design and performance of the mini-CIMS itself, rather than on the equilibrator interface. The use of membrane equilibrators in this study is not meant to indicate that they are the only, or necessarily the best interface for unattended deployment. The greenhouse gas $\left(\mathrm{CO}_{2}, \mathrm{~N}_{2} \mathrm{O}\right)$ and halocarbon communities have had considerable success with shower-head style equilibrators and similar devices should be examined for use with DMS (Johnson, 1999). The moderate solubility of DMS in seawater means that equilibrium with the gas phase is easily achieved. However, the biological issues associated with DMS analysis make equilibrator design more challenging. This is because of the potential for spurious DMS production in the equilibrator due to: 1) growth of DMS-producing organisms, or 2) rupture of phytoplankton cells and colonies as they pass through the scientific seawater system and equilibrator (Kiene and Slezak, 2006). The experience from this and prior studies (Marandino et al., 2007) suggests that the porous Teflon tube membrane equilibrator does not experience biofouling in oligotrophic conditions and certain bloom conditions. A rigorous comparison between the DMS levels in a ship's seawater pumping system and in discrete water samples has not yet been conducted. Similarly, intercomparison of membrane equilibrators, shower-type equilibrators and traditional purge/trap measurements are needed to validate these techniques under a variety of oceanographic conditions.

The atmospheric pressure, chemical ionization approach used in this study is likely to have adequate sensitivity and selectivity for many other dissolved gases in seawater which have strong proton affinities. Such molecules include unsaturated organics, oxygenates (ketones, aldehydes, and alcohols), nitriles, and amines. Measurements of acetone in seawater using a membrane equilibrator/APCI-MS have already been published, and isoprene detection has recently been demonstrated (Marandino et al., 2005; Marandino et al., unpublished data). Each of these gases has its own challenges in terms of biological interactions, surface interaction with tubing walls, contamination by material outgassing, and isobaric interferences that could affect the accuracy, precision, and temporal resolution of shipboard measurements. However, such issues can likely be addressed through careful system design and testing.

Acknowledgements. The authors thank Stanford Research Systems for their assistance in understanding the SRS RGA. We especially thank Scott Miller, collaborator and PI of the Knorr 2007 cruise, Liz Caparelli, the Woods Hole Marine Department, and the Captain and crew of the R/V Knorr. This research was funded by the National Science Foundation Atmospheric Chemistry Program (ATM-0426314) and is a contribution to the US SOLAS program.

Edited by: M. Hoppema

\section{References}

Andreae, M. O. and Barnard, W. R.: Determination of trace quantities of dimethyl sulfide in aqueous solutions, Anal. Chem., 55, 608-612, 1983.

Bandy, A. R., Thornton, D. C., Tu, F. H., Blomquist, B. W., Nadler, W., Mitchell, G. M., and Lenschow, D. H.: Determination of the vertical flux of dimethyl sulfide by eddy correlation and atmospheric pressure ionization mass spectrometry (APIMS), J. Geophys. Res.-Atmos., 107, 4743, doi:10.1029/2002JD002472, 2002.

Bates, T. S., Cline, J. D., Gammon, R. H., and Kelly Hansen, S. R.: Regional and seasonal variations in the flux of oceanic dimethylsulfide to the atmosphere, J. Geophys. Res.-Oceans, 92, 29302938, 1987.

Campargue, R.: Progress in overexpanded supersonic jets and skimmed molecular beams in free-jet zones of silence, J. Phys. Chem., 88, 4466-4474, 1984.

Dacey, J. W. H., Wakeham, S. G., and Howes, B. L.: Henry law constants for dimethylsulfide in fresh-water and seawater, Geophys. Res. Lett., 11, 991-994, 1984.

Dacey, J. W. H., Howse, F. A., Michaels, A. F., and Wakeham, S. G.: Temporal variability of dimethylsulfide and dimethylsulfoniopropionate in the Sargasso Sea, Deep-Sea Res. I, 45, 20852104, 1998.

Johnson, J. E.: Evaluation of a seawater equilibrator for shipboard analysis of dissolved oceanic trace gases, Anal. Chim. Acta, 395, 119-132, 1999.

Kelly, T. J. and Kenny, D. V.: Continuous determination of dimethylsulfide at part-per-trillion concentrations in air by atmospheric-pressure chemical ionization mass spectrometry, Atmos. Environ. A, 25, 2155-2160, 1991.

Kettle, A. J., Andreae, M. O., Amouroux, D., Andreae, T. W., Bates, T. S., Berresheim, H., Bingemer, H., Boniforti, R., Curran, M. A. J., DiTullio, G. R., Helas, G., Jones, G. B., Keller, M. D., Kiene, R. P., Leck, C., Levasseur, M., Malin, G., Maspero, M., Matrai, P., McTaggart, A. R., Mihalopoulos, N., Nguyen, B. C., Novo, 
A., Putaud, J. P., Rapsomanikis, S., Roberts, G., Schebeske, G., Sharma, S., Simo, R., Staubes, R., Turner, S. and Uher, G.: A global database of sea surface dimethylsulfide (DMS) measurements and a procedure to predict sea surface DMS as a function of latitude, longitude, and month, Global Biogeochem. Cy., 13, 399-444, 1999.

Kiene, R. P. and Slezak, D.: Low dissolved DMSP concentrations in seawater revealed by small-volume gravity filtration and dialysis sampling, Limnol. Oceanogr. Meth., 4, 80-95, 2006.

Marandino, C. A., De Bruyn, W. J., Miller, S. D., Prather, M. J., and Saltzman, E. S.: Oceanic uptake and the global atmospheric acetone budget, Geophys Res Lett, 32, L15806, doi:10.1029/2005GL023285, 2005.

Marandino, C. A., De Bruyn, W. J., Miller, S. D., and Saltzman, E. S.: Eddy correlation measurements of the air/sea flux of dimethylsulfide over the North Pacific ocean, J Geophys ResAtmos, 112, D03301, doi:10.1029/2006JD007293, 2007.

Marandino, C. A., De Bruyn, W. J., Miller, S. D., and Saltzman, E. S.: DMS air/sea flux and gas transfer coefficients from the North Atlantic summertime coccolithophore bloom, Geophys. Res. Lett., 35, L23812, doi:10.1029/2008GL036370, 2008.

Marandino, C. A., De Bruyn, W. J., Miller, S. D., and Saltzman, E. S.: Open ocean DMS air/sea fluxes over the eastern South Pacific ocean, Atmos. Chem. Phys., 9, 345-356, 2009, http://www.atmos-chem-phys.net/9/345/2009/.

Nemcek, N., Ianson, D., and Tortell, P. D.: A high-resolution survey of DMS, $\mathrm{CO}_{2}$, and $\mathrm{O}_{2} / \mathrm{Ar}$ distributions in productive coastal waters, Global Biogeochem. Cy., 22, GB2009, doi:10.1029/2006GB002879, 2008.
Park, K. T. and Lee, K.: High-frequency, accurate measurement of dimethylsulfide in surface marine environments using a microporous membrane contactor, Limnol. Oceanogr. Meth., 6, 548557, 2008.

Simo, R. and Dachs, J.: Global ocean emission of dimethylsulfide predicted from biogeophysical data, Global Biogeochem. Сy., 16, 1078, doi:10.1029/2001GB001829, 2002.

Spicer, C. W., Kenny, D. V., Chapman, E., Busness, K. M., and Berkowitz, C. M.: Observations of dimethyl sulfide over the western North Atlantic Ocean using an airborne tandem mass spectrometer, J. Geophys. Res.-Atmos., 101, 29137-29147, 1996.

Sunner, J., Nicol, G., and Kebarle, P.: Factors determining relative sensitivity of analytes in positive mode atmospheric-pressure ionization mass spectrometry, Anal. Chem., 60, 1300-1307, 1988.

Sunner, J., Ikonomou, M. G., and Kebarle, P.: Sensitivity enhancements obtained at high-temperatures in atmospheric-pressure ionization mass spectrometry, Anal. Chem., 60, 1308-1313, 1988.

Tortell, P. D.: Small-scale heterogeneity of dissolved gas concentrations in marine continental shelf waters, Geochem. Geophys. Geosys., 6, Q11M04, doi:10.1029/2005GC000953, 2005.

Tortell, P. D.: Dissolved gas measurements in oceanic waters made by membrane inlet mass spectrometry, Limnol. Oceanogr. Meth., 3, 24-37, 2005.

Turner, S. M. and Liss, P. S.: Measurements of various sulfur gases in a coastal marine environment, J. Atmos. Chem., 2, 223-232, 1985 . 